Produto \& Produção, vol. 6, n. 1 p. 33-45, fev. 2002

$\mathbf{P P}$

\title{
Fatores influentes na adoção de métodos de custeio em pequenas empresas : estudo multicasos
}

\author{
Flávia Gutierrez Motta \\ Mestre em Engenharia de Produção pela Escola de Engenharia de São Carlos - USP (Pesquisa FAPESP) e Douto- \\ randa em Engenharia de Produção pela Escola Politécnica - USP. Email: fgmotta@yahoo.com \\ Edmundo Escrivão Filho \\ Doutor em Engenharia de Produção, Professor do Programa de Pós-Graduação em Engenharia de Produção da \\ Escola de Engenharia de São Carlos - USP
}

Este artigo analisa dois objetos de estudo, pequenas empresas e métodos de custeio, com o objetivo de identificar os fatores que levam as pequenas empresas a adotarem um método de custeio específico. Para alcançar tal objetivo, e utilizando a metodologia de multicasos exploratória e descritiva, foram estudadas quatro pequenas empresas do ramo metal-mecânico, buscando maiores informações sobre o problema estudado. O estudo identificou que o nível de pessoalidade/impessoalidade presente na filosofia administrativa das empresas determina a escolha de um método de custeio específico.

Palavras-chave: pequenas empresas; métodos de custeio.

This article analyzes two objects of study, small companies and costing methods, in order to identify the factors that take the small companies to adopt a specific costing method. To reach such objective, and using exploratory and descriptive methodology they were studied four metal-mechanic companies, looking for further information about the problem. The study identified that the impersonal/personal level in the company administrative philosophy defines the adoption of a specific costing method.

Keywords: small companies; costing methods.

\section{Introdução}

A contabilidade de custos nas empresas é um sistema que processa dados visando gerar informações para a gestão administrativa dos custos da empresa. Esse sistema é utilizado pela maioria das empresas industriais, em todo o mundo. Porém existem vários métodos de custeio, que geram informações diferentes, e as empresas utilizam métodos diversos de acordo com as suas contingências.

Em se tratando de métodos de custeio, os principais, segundo Guerreiro (1999), encontrados nas empresas são: custeio por absorção, custeio pleno ou integral, custeio direto ou variável, custeio pelas unidades de esforço de produção, custeio baseado em atividades e a contabilidade de ganhos. Esses métodos de custeio tratam os dados que entram no sistema de formas diferentes e assim geram informações de custos que são indicados para situações diferentes. Dessa forma, quando uma empresa for implementar um método de custeio, é necessário que ela avalie as características organizacionais (internas às empresas) e as características contextuais (externas às empresas) para que ao optar por um método específico este esteja adequado às necessidades da empresa. A análise racional desses fatores leva a empresa a obter uma ferramenta gerencial importante para seu sucesso.

Porém, nas pequenas empresas, onde o papel gerencial muitas vezes é exercido pelo próprio empreendedor, os fatores impessoais (organizacionais e contextuais) não são os únicos que condicionam a decisão de adoção de um método de custeio, mas também fatores pessoais. Estes fatores pessoais podem condicionar a escolha de um método de custeio impedindo uma análise mais racional. 
Assim, o objetivo deste artigo é entender como uma pequena empresa adota um determinado método de custeio, ou seja, quais os fatores que condicionam essa decisão. Para alcançar o objetivo proposto foi realizado trabalho de campo junto a quatro pequenas empresas do setor metal-mecânico. Este estudo visou entender e explorar o problema da escolha de métodos de custeio pelas empresas estudadas. Considerada mais apropriada à natureza e ao objetivo da pesquisa, a metodologia escolhida foi o estudo de multicasos exploratório e descritivo.

A pesquisa descritiva se caracteriza por observar, registrar, analisar e correlacionar fatos ou fenômenos sem manipulá-los. Na verdade, tal pesquisa procura descobrir a freqüência de ocorrência de um fenômeno; a relação e conexão com outros; sua natureza e características. Já os estudos exploratórios têm por objetivo buscar maiores informações sobre determinado assunto de estudo. Isso é recomendável quando há pouco conhecimento sobre o problema a ser estudado. Assim, tais estudos têm por objetivo familiarizar-se, ou obter nova percepção, novas idéias de um fenômeno (Bervian \& Cervo, 1996).

Portanto, este estudo foi exploratório no sentido de permitir um aumento de experiência em torno do problema da escolha dos métodos de custeio nas pequenas empresas, pois são raros os autores que buscam analisar esse assunto. De acordo com esse referencial metodológico, os resultados encontrados são considerações preliminares que trazem uma nova visão sobre a questão dos métodos de custos.

Por meio do estudo das quatro pequenas empresas ficou evidente que a filosofia administrativa da empresa é o condicionante primário na adoção do método de custeio. Portanto essa ferramenta gerencial depende muito mais da administração da empresa do que de considerações técnicas com relação às melhores práticas indicadas pelos teóricos de custos.

O trabalho está dividido em sete seções: nesta primeira são apresentados os objetivos do trabalho; na segunda são explicitados os conceitos de método de custeio e descritos os principais métodos existentes, com o propósito de subsidiar os pesquisadores nas discussões técnicas realizadas nas empresas e de proporcionar aos leitores uma visão sobre as diversas formas de apuração de custos; na terceira seção discute-se o papel de sistemas de informações de custos em pequenas empresas e as peculiaridades destas; na quarta seção são apresentadas as características gerais das empresas estudadas na pesquisa de campo, a fim de contextualizar o estudo; na quinta seção são descritos os métodos adotados por cada empresa e como são operacionalizados estes métodos; na sexta seção analisam-se os fatores que condicionaram a adoção dos métodos pelas empresas bem como identificada-se qual fator teve maior peso na definição do método; e na última são apresentadas as considerações finais.

\section{Métodos de custeio}

O sistema de informações de custos é constituído de três subsistemas que acumulam e processam os dados gerando as informações de custos, a saber: 1) método de custeio; 2) sistema de custeio; e 3) sistema de identificação e acumulação de custos. Segundo Guerreiro (1999), o método de custeio é um desses três subsistemas e representa a parte do sistema na qual os dados são processados, gerando as informações para os administradores; constitui, portanto, a parte principal do sistema.

Para Guerreiro (1999), o método de custeio é o subsistema que faz a seleção dos custos e/ou despesas e apropria-os aos objetos de custeio (produtos, departamentos, clientes etc). Segundo Alves (1997), os métodos de custeio visam determinar os critérios para apuração dos custos dos fatores produtivos a determinados níveis de interesse das entidades (produto, atividade, departamento, empresa etc.).

Os métodos de custeio básicos são: custeio direto e full cost. Existem vários outros métodos que derivam destes dois, que são (Guerreiro, 1999): custeio por absorção, custeio pleno, custeio baseado em atividades (ABC) e o custeio das unidades de esforço de produção (UEP), que se baseia no custeio full cost; custeio direto e contabilidade de ganhos da TOC (teoria das restrições) que são baseados no custeio direto. Esses vários métodos de custeio possuem objetivos e pressupostos diferentes, geram informações de custos diferentes e, portanto, são indicados para situações diferentes, dependendo da necessidade de informações da empresa.

Custeio por Absorção consiste na apropriação de todos os custos de produção, e somente os custos de produção, aos bens elaborados através de rateios baseados em volume. Este método é derivado da aplicação dos princípios de contabilidade geralmente aceitos. Segundo Gonçalves et al. (1998) o objetivo é de avaliar estoques e fornecer informações para fins de legislação, portanto não se importa com a relevância das informações para administração do negócio. Devido a isto é um método que muitas vezes falha se utilizado como instrumento gerencial, pois adota critérios aleatórios para o rateio dos custos indiretos o que resulta em distorções na apuração dos efetivos custos dos produtos e, portanto pode levar falsas informações de custos para os administradores (Perez Júnior et al., 1999). 
O custeio pleno é método que surgiu na Alemanha com intuito de estabelecer preço de venda de produtos, para isto o método rateia todos os gastos da empresa (tanto custos como despesas) para os produtos. Se os rateios utilizados fossem perfeitos o RKW forneceria o gasto completo da empresa com cada produto, porém eles são realizados baseados em critérios arbitrários (como no custeio por absorção) assim o custo final do produto é distorcido. Segundo Martins (1998) a adoção de preços estabelecidos por este método é viável apenas em economias de decisão totalmente centralizada, ou em mercados absolutamente monopolísticos. Como método de custeio o RKW não deve ser utilizado para fins gerenciais devido aos mesmos motivos da não utilização do custeio por absorção.

O custeio ABC descreve a forma como uma empresa emprega tempo e recursos para atingir determinados objetivos (Ching, 1997). Ou seja, o custeio ABC busca um maior entendimento da estrutura interna de uma organização através da compreensão dos seus processos para gerar informações de suporte para uma tomada de decisão estratégica e operacional baseada na forma como os recursos da empresa são utilizados (Paixão \& Kliemann Neto, 2002). Para isto o ABC elimina os rateios simplistas praticados pela contabilidade tradicional, que não identificam claramente a utilização variada de recursos, e adota alocações mais precisas baseadas nas atividades realizadas pela empresa e no consumo destas atividades pelos produtos. O ABC pode auxiliar na remoção de perdas dos custos não agregadores de valor e da capacidade não utilizada, e busca entender o que gera tais custos e por quem são consumidos. Segundo IOB (1998) o $\mathrm{ABC}$ é indicado para empresas cujos custos indiretos representam parcela significativa dos seus custos industriais totais; que tenham um processo produtivo complexo; que trabalham com clientela diversificada.

O método das unidades de esforço de produção (UEP) racionaliza o processo de gestão industrial definindo uma unidade de medida comum, a qual transforma uma fábrica multiprodutora em uma fábrica monoprodutora, que produz um único artigo fictício equivalente aos vários produtos reais (Antunes Júnior et al., 1991). Segundo Kraemer \& Kliemann Neto (1994) sua maior contribuição é a apropriação conveniente dos custos indiretos de fabricação dos produtos, portanto está direcionado para resolver a problemática de informes de custo do chão-de-fábrica, tendo também o objetivo de gerenciar e controlar a produção. As desvantagens do método, segundo os mesmos autores, estão na forma de distribuição das despesas administrativas que é arbitrária, e na incapacidade de identificar melhorias no processo, pois supõe que as atividades permanecem constantes ao longo do tempo.
O Custeio Direto é o método que apropria apenas custos variáveis aos produtos, e os custos fixos são separados e considerados como despesas do período. Este método fornece a margem de contribuição para análises administrativas, identifica de forma clara o relacionamento custo-volume-lucro, e facilita a preparação imediata dos instrumentos de controle como custo-padrão e análise break-even point (National Association of Accountings apud Santos, 1998). O problema da utilização deste método apontado por Florentino (1983) é a aplicação em empresas onde os custos variáveis representam uma pequena parcela no custo de produção do produto, e os custos fixos grande parcela. Porém, as empresas vêm cada vez mais realizando substituições de custos variáveis por fixos, com maior investimento em tecnologias, e por conseqüência as despesas variáveis estão reduzindo (Kraemer, 1995).

A contabilidade de ganhos tem por objetivo apoiar a tomada de decisões das empresas que utilizam a Teoria das Restrições (TOC) como filosofia de produção. Assim como o custeio direto a contabilidade de ganhos não rateia gastos fixos e, portanto não incorre em erros de alocação de custos aos produtos. As decisões são tomadas baseadas na análise do comportamento do ganho, inventário e da despesa operacional, buscando sempre um aumento da primeira medida, e diminuição das outras duas (Corbett Neto, 1997). Segundo Catelli et al. (1997) a visão da contabilidade de ganhos segue linha da gestão de resultados econômicos, não se baseando na visão limitada de gerir analisando apenas custos. A desvantagem deste método é que considera apenas o nível de atividades atual da empresa, assim as decisões estratégicas de longo prazo podem ser prejudicadas.

Esses métodos de custeio são ferramentas que geram informações diferentes, pois possuem procedimentos completamente distintos. Assim, dentro de uma visão de eficácia e eficiência, é esperado que o administrador escolha seu método de custeio segundo fatores racionais que potencializem a adequação do mesmo às necessidades da empresa e não por simples facilidade de acesso ou por gosto do contador.

\section{Papel de um sistema de informa- ções de custos na pequena empresa}

Segundo Zimmerer \& Scarborough (1994), a sobrevivência das pequenas empresas depende de sua habilidade em gerar lucros. No entanto, a geração de lucros de uma empresa não ocorre ao acaso, isso requer um planejamento cuidadoso e muitas análises gerenciais.

O conhecimento dos custos das empresas no ambiente atual de competitividade é essencial, uma vez que o 
lucro é determinado pelo preço, que já está estabelecido pelo mercado, menos os custos da empresa; portanto, para aumentar o lucro, a empresa deve reduzir custo e não aumentar preços.

Um sistema de controle e análise de custos bem organizado, apropriado aos objetivos da empresa, preciso e atualizado, mostra à empresa o que está acontecendo, servindo de base para a administração tomar decisões sobre como melhor alocar os recursos disponíveis, com o objetivo de otimizar os resultados.

Um sistema de custeio eficiente pode ser a chave de sucesso de um empreendimento (SEBRAE apud Kassai, 1996), já que este se constitui em uma ferramenta de auxílio para o gestor tomar decisões objetivando: determinar o custo dos produtos como um dos critérios da fixação de preços; analisar a rentabilidade das diversas atividades e produtos da firma; avaliar os estoques; determinar a estrutura de custos dos produtos e compará-la com a concorrência; realizar simulações variando as condições de compras de matérias-primas, terceirizações, investimentos, eliminação de produtos etc, para empregar os recursos (que são escassos) onde produzam melhores resultados. Com esses dados, ocorre uma melhoria na qualidade das decisões tomadas pela empresa, o que aumenta sua competitividade.

A falta de um sistema eficaz de contabilidade de custos não é apenas um problema contábil, e sim um problema administrativo, pois sem esse controle adequado, não se consegue compreender a empresa, e os resultados podem ser desastrosos: a empresa pode começar a promover mercadorias e serviços, ou apostar em projetos que não agregam nenhum lucro; pode se perder e não saber mais quais produtos estão vendendo bem e quais estão dando prejuízo, e na melhor das hipóteses o administrador terá apenas uma idéia vaga de onde o dinheiro está indo e de qual é a situação da empresa (Resnik, 1990).

Assim, o papel a ser desenvolvido por um sistema de custos em uma pequena empresa não difere muito em relação ao desempenhado na grande empresa, isto é, a responsabilidade pela estruturação de um sistema de informações de apoio à decisão de forma a auxiliar a empresa na busca pela melhor utilização de recursos para o alcance da eficácia empresarial.

Porém, um sistema de apoio à decisão nas grandes empresas deve ser complexo e completo de forma a retratar suas operações. Para isso, a grande empresa conta com grupos de especialistas para auxiliar o gestor no momento de decisão e esses sistemas são, na maioria das vezes, informatizados sendo capazes de fornecer informações em tempo real.
Já as pequenas empresas apresentam especificidades que devem ser levadas em conta no planejamento da implantação do método. Leone (1999, p.92-3) apresenta uma tipologia de especificidades divididas em três grandes grupos:

a) especificidades organizacionais:

- maior centralização com estrutura organizacional simples;

- menor controle sobre seu ambiente externo;

- os processos de planejamento e controle são pouco formalizados e quantificados;

- lógica de reação e adaptação ao ambiente;

- personalização da gestão na pessoa do seu proprietário-dirigente;

b) especificidades decisionais:

- tomada de decisão baseada na experiência, no julgamento ou na intuição;

- o sistema de valores do proprietário-dirigente marca a definição de políticas;

- o poder de decisão é localizado e centralizado;

c) especificidades individuais:

- papel preponderante de um só indivíduo na organização;

- a existência e o funcionamento da empresa depende da trajetória pessoal do dirigente;

- o dirigente tem papel paternalista em relação aos seus funcionários.

Na escolha e implantação de um método de custeio em pequenas empresas deve-se levar em conta a simplicidade da estrutura organizacional e os escassos recursos humanos e financeiros; assim, um planejamento prévio cuidadoso é necessário para que os objetivos com a implantação de um método de custeio sejam alcançados com eficácia. Dois pontos críticos devem ser cuidadosamente planejados na escolha de um método específico de custeio: se as informações geradas pelo método adotado são as de que a empresa necessita; e planejar o nível de detalhamento que será adotado para o sistema. O planejamento do nível de detalhamento é essencial, pois é aqui que se determina o quão preciso será o método e os recursos necessários para sua operacionalização.

\section{Estudos empíricos}

Os estudos aqui descritos foram realizados no final de 1999 na cidade de São Carlos - SP. Os dados foram 
coletados através de análises de documentos da empresa, questionários e entrevistas. Os questionários e as entrevistas foram respondidos pelos operadores dos sistemas de custos e pelos principais administradores das quatro empresas analisadas.

\subsection{Descrição da empresa A}

A empresa A atua no ramo de eletrodomésticos de linha branca, produzindo lavadoras semi-automáticas e secadoras centrífugas. Possui 67 funcionários, sendo que 37 atua na administração e 30 no operacional.

A empresa se estruturou como uma montadora, adquire todos os componentes necessários e apenas monta os produtos. Sua linha monta cinco diferentes modelos de lavadoras e uma centrífuga, porém $70 \%$ dos componentes das lavadoras são iguais, assim pode-se considerar que a empresa produz um produto padrão com poucas variações.

Esse ramo é altamente competitivo, a empresa A compete com grandes empresas e detêm $8 \%$ do mercado, ficando entre terceiro e quarto lugar em vendas.

Os proprietários da empresa são dois sócios que possuem 70,5\% e BNDESpar com 29,5\%. Os dois sócios trabalham na empresa, sendo que um é responsável pela diretoria comercial e financeira e o outro pela diretoria de operações.

Os responsáveis pelo sistema de custos são: a controladoria, que o operacionaliza, e o diretor da área comercial e financeira que é usuário direto das informações geradas. Dessa forma, as informações de custos são analisadas pela cúpula da empresa e apenas a operacionalização fica a cargo dos chamados coordenadores de áreas (pessoas responsáveis pelos departamentos).

\subsection{Descrição da empresa $B$}

A empresa B atua no ramo de eletrodomésticos de linha branca, fabricando bebedouros, e presta serviços para outras empresas, de ferramentaria, estamparia, conformação de tubos, pintura eletrostática a pó, montagens elétricas e mecânicas, e também revende produtos importados como aquecedores e freezeres a gás. Possui 87 funcionários, sendo 42 na administração e 45 no operacional.

Sua linha de produção fabrica nove modelos de bebedouros que representam $85 \%$ do faturamento, a prestação de serviços representa $10 \%$ do faturamento e a revenda de produtos é responsável por $5 \%$ do faturamento.
Esse mercado é altamente competitivo, o preço é um dos fatores decisivos para a colocação do produto no mercado. A empresa atua no mercado nacional e detem aproximadamente $30 \%$, ficando em segundo lugar em vendas. Seu mercado principal está na região nordeste, mas a empresa está investindo para aumentar sua participação no sudeste, onde sua principal concorrente possui uma melhor colocação dos produtos.

A empresa é constituída por uma sociedade entre uma empresa uruguaia, que possui $95 \%$ do capital, e uma advogada brasileira com $5 \%$.

O diretor comercial juntamente com o gerente de vendas são usuários diretos das informações geradas pela Contabilidade de Custos, que é operacionalizada pelo departamento de Contabilidade com auxílio de uma pessoa que presta serviço para a empresa (terceirizada). O terceiro é o principal responsável pelas informações gerenciais de custos, as quais são analisadas mensalmente pelo Diretor geral/comercial e pelo gerente de vendas.

\subsection{Descrição da empresa $C$}

A empresa $\mathrm{C}$ atua no ramo de usinagem de peças, prestando serviços para várias empresas. Os produtos que ela produz são encomendados pelos clientes, e a empresa recebe o projeto da peça, as especificações dos materiais que devem ser utilizados e também algumas ferramentas para a produção das peças. Possui 52 funcionários, sendo 43 pessoas no operacional e 9 na administração.

A empresa tem três clientes principais: o mais importante consome $70 \%$ da produção da empresa, o segundo $25 \%$ e o terceiro $5 \%$. Esses clientes estão concentrados na região de Campinas e São Carlos.

Os proprietários dessa empresa são um casal, sendo que cada um possui $50 \%$ do capital da empresa.

Quanto à organização administrativa, o empresário e o engenheiro concentram a maioria das funções. Com relação ao método de custeio, o responsável pela operacionalização dos custos e o usuário direto das informações geradas é o próprio empresário.

\subsection{Descrição da empresa $D$}

O proprietário da empresa D é irmão do proprietário da empresa $\mathrm{C}$, e ambos atuam no mesmo ramo: prestação de serviços de usinagem de peças. Essa empresa possui as mesmas características da empresa C, ou seja, é uma empresa do setor metal-mecânico 
tradicional. A empresa possui 65 funcionários, sendo 12 na administração e 53 no operacional.

A empresa possui três clientes principais: uma grande empresa que atua na cadeia automobilística e consome $50 \%$ da produção, e duas empresa que atuam no ramo de eletrodomésticos de linha branca respondendo cada uma por $22,5 \%$ da produção. A atuação geográfica da empresa é regional, todos os clientes se situam na região de Campinas e São Carlos.

Os proprietários da empresa são dois empresários da cidade, um detém 98,33\% do capital e o seu cunhado $1,67 \%$.

O sistema de custos é operacionalizado pelo engenheiro da empresa, e o principal usuário das informações geradas é o próprio empresário.

\section{Método de custeio utilizado pelas empresas}

Antes de descrever os fatores que condicionaram a adoção de determinado método de custeio pelas empresas, é necessário descrever quais são os métodos utilizados. Assim, abaixo estão descritos quais os objetivos das empresas com a utilização dos métodos, quais os objetos custeados, qual é o método utilizado e qual a sistemática de utilização das informações de custos pela administração.

\subsection{Empresa A}

O principal objetivo do método de custeio para a empresa A é gerenciar os custos e despesas que são realmente administráveis pela empresa.

Os objetos de custeio são dois: os produtos e os departamentos (Centros de Custos).

A empresa utiliza juntamente com o sistema de custos a ferramenta de orçamentação empresarial. Essa ferramenta tem por objetivo monitorar os gastos que são de responsabilidade dos departamentos. Essa é uma forma de designar responsáveis para cada gasto realizado pela empresa, pois os chefes de cada departamento devem responder pelas variações de gastos não planejadas que por ventura ocorram.

O planejamento orçamentário é realizado anualmente, com revisões trimestrais. A cada três meses, os responsáveis pelos departamentos devem responder pelos gastos realizados, sendo que os gastos devem estar de acordo com o que foi planejado. Se houver discrepância, esta será analisada e ações de ajustes são tomadas.
A frequiência de cálculo dos custos dos produtos é mensal.

Os gastos não são separados em despesas e custos, mas em fixos ou variáveis. Sendo que os gastos fixos representam $25 \%$, e os variáveis $75 \%$ dos gastos totais da empresa.

O método utilizado pela empresa é o direto ou variável.

Os preços dos produtos são determinados por dois critérios: através do estabelecimento de uma margem de contribuição que a empresa julga necessária para cobrir seus gastos fixos e ainda gerar lucro, e pelo acompanhamento da evolução dos preços no mercado.

Todo mês, o responsável pela controladoria repassa ao diretor comercial e financeiro um relatório de uma página com os resultados do mês anterior. Com essas informações o empresário controla as vendas, os preços praticados e os custos das matérias-primas.

\subsection{Empresa B}

O principal objetivo do método de custeio para a empresa B é calcular o custo real dos produtos para que se estabelecerem preços de vendas; analisar a evolução dos custos e das vendas; e para que a direção da empresa tenha informações para tomar decisões administrativas como: diminuir custos, melhorar rentabilidade de produtos, analisar produtos que não sejam rentáveis etc.

Os objetos de custeio são os produtos e as áreas da empresa.

As áreas da empresa são custeadas com o objetivo de planejamento dos gastos. A cada início de ano, a empresa faz o planejamento dos seus gastos para o ano seguinte, e cada área recebe um orçamento mensal. Esse planejamento é acompanhado mês a mês para verificar se as áreas estão cumprindo o planejado. Os custos dos produtos também são acompanhados mensalmente pela diretoria da empresa com o objetivo de controle e melhoria.

O sistema de custos está passando por um processo de aprimoramento com o objetivo de melhorar o controle dos dados de entrada do sistema (controle de estoques final, intermediário e de matéria-prima, valorizar os custos dos materiais através do custo de reposição e acompanhar melhor os materiais que são enviados para realização de serviços em terceiros) e uniformizar o sistema computacional utilizado pelos departamentos. Na verdade, é um trabalho que visa, 
portanto, acurar os dados que são utilizados pelo sistema, para que as informações geradas tenham maior credibilidade.

Todos os gastos incorridos pela empresa são divididos em custos e despesas. As despesas são alocadas diretamente para o Demonstrativo de Resultados e os custos divididos entre diretos (representam $80 \%$ dos custos totais) e indiretos (representam 20\% do total). A separação entre custos diretos e indiretos é realizada corretamente. Não é realizada a separação entre custos fixos/variáveis, no entanto a empresa calcula o ponto de equilíbrio para a empresa como um todo.

O método de custeio utilizado é o absorção.

Os preços de venda são determinados aplicando-se mark-up sobre os custos.

O resultado da composição do preço é o "preço ideal", que representa o objetivo da empresa. Além do "preço ideal", é realizado o cálculo do "preço mínimo", que representa a aplicação do mark-up considerando margem de lucro zero. Esse intervalo entre o preço mínimo e o ideal é o intervalo no qual a empresa negocia suas vendas.

A empresa analisa as informações geradas pelo sistema de custeio sistematicamente. No dia 5 de todo mês, é realizado o levantamento dos custos dos produtos fabricados e das vendas do mês anterior. Essas informações são relatadas para a diretoria. No dia 8, é realizada uma reunião com os diretores (administrativo, comercial e industrial), o gerente de vendas e o responsável pela operacionalização do sistema de custos, para que eles tomem ciência do resultado geral do mês anterior e para planejarem as ações futuras. As decisões são tomadas no sentido de controlar os custos, verificando se ocorreu alguma modificação; verificar se as quantidades vendidas estão de acordo com o que foi planejado; verificar a rentabilidade alcançada e revisar os preços praticados.

\subsection{Empresa C}

A empresa $\mathrm{C}$ desenvolveu um método próprio para fazer orçamentos e apurar os custos da empresa. Esse método está implementado há mais de oito anos.

O próprio empresário foi quem desenvolveu o método utilizado, que com a ajuda de um programador, foi passado para uma linguagem computacional. Isso ocorreu quando um grande cliente da empresa pediu uma planilha de custos para as peças que seriam produzidas.

O principal objetivo do sistema é calcular os custos dos produtos para que eles sejam competitivos no mercado e para cobrar um preço justo dos clientes.

O sistema custeia apenas os produtos, mas, uma vez por ano, o empresário faz o estudo da rentabilidade que os clientes trazem para a empresa. Nesse estudo são avaliadas quais são as peças vendidas aos clientes e quanto que cada cliente rende para a empresa. O objetivo é ter uma visão global dos negócios com cada cliente, determinar os mais rentáveis e verificar se algum cliente está trazendo prejuízo.

O sistema possui duas etapas: orçamento das peças e apuração do real.

Não há separação entre custos e despesas, nem entre custos diretos/indiretos ou fixos/variáveis. Pelo menos essas divisões não seguem as recomendações teóricas.

Para realizar o orçamento de uma peça, o empresário determina em quais máquinas aquele material será processado e também quais os centros de custos (C.C.) que serão acionados. Com os dados do custo horário de cada centro de custo e da produção horária desses centros (padrão) é calculado o custo de cada fase produtiva (custo de homem-máquina/hora). A somatória dos custos das fases resulta no custo produtivo da peça.

Tabela 1 - Exemplo de cálculo do custo das fases produtivas de uma peça

\begin{tabular}{|l|l|c|c|c|c|}
\cline { 2 - 6 } \multicolumn{1}{|c|}{ Fluxo Produtivo } & C.C. & Custo/Hora & Prod/Hora & Custo da fase \\
\hline 1 & Corte e furo do centro & 55 & 19,20 & 115 & 0,16695 \\
\hline 2 & Usinagem e laminação da rosca & 55 & 19,20 & 95 & 0,20210 \\
\hline 3 & Cortar engrenagem & 55 & 19,20 & 114 & 0,16842 \\
\hline 4 & Desgaste do corpo & 18 & 23,05 & 265 & 0,08698 \\
\hline 5 & Acabamento do corpo & 40 & 20,80 & 221 & 0,09411 \\
\hline
\end{tabular}


No custo horário dos centros de custos estão incluídos todos os gastos realizados pela empresa (menos matéria-prima): mão-de-obra direta e indireta, benefícios para os funcionários (cesta básica, plano de saúde, refeições e transporte), depreciação do equipamento (que é sempre o valor de reposição do equipamento dividido pela vida útil), energia elétrica, manutenção, carros da empresa, telefone, água, imposto predial municipal, aluguel, ferramentas utilizadas nos equipamentos, materiais de consumo da produção. Todos esses gastos são convertidos em custo por hora.

Os gastos que o empresário considera como indireto (mão-de-obra indireta, carros da empresa, telefone, água, imposto predial municipal, aluguel) são divididos pelo número total de funcionários. Seria um rateio dos gastos indiretos, apesar dessa divisão estar distante do que é considerado direto e indireto pela teoria.

Para se obter o custo de fabricação da peça, aplicamse sobre o custo de produção já apurado $20 \%$ de lucro sobre a produção, soma-se o custo da matériaprima aplicada na peça incluindo $20 \%$ de lucro sobre a administração da matéria-prima, somam-se os custos com tratamento superficial ou térmico (se for realizado fora da empresa) aplicando-se $20 \%$ de lucro sobre administração de serviço, e também soma-se o imposto de renda sobre os lucros.

Para se obter o preço orçado, que será repassado ao cliente, é necessário ainda somar impostos (PIS/ COFINS, ICMS, IPI), despesas com representação, frete e custo financeiro (quando as condições de pagamento forem para 30 dias).

Esse é o sistema que calcula o chamado Custo Padrão.

O cálculo dos custos reais segue a mesma sistemática do cálculo do padrão, só que em vez das quantidades padrão de produção das várias fases produtivas temse a quantidade real produzida.

O levantamento dos custos reais é realizado apenas quando ocorre alguma modificação importante que possa impactar nos custos que já estão calculados.

Através da análise das informações obtidas não é possível classificar o método de custeio utilizado como nenhum dos métodos estudados na teoria.

O cálculo dos custos não segue uma sistemática. Como o empresário acumula várias funções, sendo também o responsável pela operacionalização desse sistema, não se determinou uma freqüência a ser seguida. Na verdade, apenas quando há alguma modificação representativa é que o empresário recalcula os custos dos produtos. Portanto o custo real da produção não é acompanhado.

\subsection{Empresa D}

A empresa utiliza o método de custeio desenvolvido pela empresa C. O método está implementado há mais ou menos 2 anos.

O principal objetivo do sistema é calcular os custos dos produtos.

O sistema custeia apenas os produtos, não são realizados estudos dos custos dos clientes, como a empresa $\mathrm{C}$ faz.

Para calcular o orçamento de uma peça, o empresário, juntamente com o engenheiro e os responsáveis pela produção, determina em quais máquinas será processado o material, quais serão os centros de custos acionados e as estimativas das quantidades horárias que serão produzidas nas diversas operações. Dessa forma, é estipulado o roteiro de fabricação (em quais centros de custos serão realizadas as operações e em que ordem).

Os custos produtivos das peças, os custos horários dos centros de custos e os preços são obtidos da mesma forma que a empresa $\mathrm{C}$ obtém.

O preço praticado pela empresa é o que foi estabelecido no orçamento das peças. Às vezes ocorre revisão de preços a pedido do cliente, então são realizados estudos para verificar se é possível abaixar os preços.

O cálculo dos custos não segue uma sistemática.

\section{Os fatores condicionantes na adoção dos métodos de custeio}

A razão pela qual as empresas adotam determinado método de custeio será esclarecida a seguir. Vários fatores influenciam nessa decisão: fatores impessoais (contextuais ou organizacionais) e fatores pessoais.

\subsection{Fatores condicionantes na adoção do método na empresa $\mathrm{A}$}

O método de custeio adotado pela empresa A foi definido pelos empresários.

O diretor de operações estava fazendo um curso de especialização, no qual aprendeu a sistemática do custeio direto e de outros métodos de custeio. Ele 
achou os métodos interessantes e os apresentou para o diretor comercial e financeiro. Os dois, depois de algumas análises, decidiram que o método direto era mais adequado à realidade da empresa. Segundo o diretor comercial e financeiro,

\begin{abstract}
"As empresas normalmente não possuem uma análise crítica para identificar se a ferramenta de custos utilizada é adequada para a realidade da empresa. Normalmente o contador é quem estipula a sistemática que será utilizada, só que os contadores utilizam, na maioria dos casos, custeio por absorção, e nem sempre este é o melhor método. Portanto é necessário que o empresário questione se aquilo é adequado para a sua realidade. Por exemplo, antes a empresa adotava o custeio por absorção, hoje mudamos para o direto pois julgamos ser mais apropriado. Conheço também o custeio $A B C$, mas acho que ele é muito complexo para a minha realidade de hoje, mas daqui algum tempo pode ocorrer uma modificação na minha empresa que transforme a realidade atual, $e$ que pode tornar viável a aplicação do $A B C$. Então eu tenho que ter visão crítica para identificar quando que a ferramenta utilizada se torna inadequada. Não adianta delegar esta responsabilidade ao contador, pois sou eu quem utiliza as informações geradas."
\end{abstract}

$\mathrm{O}$ diretor comercial e financeiro julga o método $\mathrm{ABC}$ muito complexo para a sua empresa, pois ela produz apenas 5 modelos de lavadora e 1 modelo de centrífuga, havendo pouca diferenciação na produção dos modelos.

A adoção do método de custeio foi, portanto, definida pelos empresários com base nos fatores impessoais. Os fatores organizacionais e contextuais foram analisados para determinar o método de custeio mais adequado para a realidade da empresa, sendo determinantes na decisão. Talvez isso tenha ocorrido devido à personalidade dos empresários que se mostraram pessoas abertas às modificações e que não se prendem a tradições administrativas.

Analisando essas informações, é possível fazer um resumo dos fatores que influenciaram a adoção do método de custeio:

- Fatores Contextuais - a concorrência do mercado da empresa A é alta; a variável preço é determinante; embora a empresa tenha uma produção considerável, o poder de barganha frente aos fornecedores é limitado. Esses fatores foram extremamente importantes para a adoção e estruturação do atual método de custeio.
- Fatores Organizacionais - a empresa tem um perfil administrativo voltado totalmente para o mercado e para o cliente; o responsável pela adoção do método de custeio foi o diretor comercial e financeiro, portanto um administrador; e a empresa possui uma boa estrutura de apoio para a administração. O fator organizacional também pesou na decisão pela adoção do método de custeio utilizado.

- Fatores Pessoais - o diretor comercial e financeiro centraliza em suas mãos as decisões estratégicas da empresa, e para isso ele necessita de informações confiáveis para as decisões; é uma pessoa ativa, inovadora, não se prende à tradição e está sempre em busca de novas tecnologias (universidades, feiras nacionais e internacionais etc). Portanto, o perfil do empresário também influenciou a adoção do método de custeio, porém, o julgamento em relação ao método mais adequado foi baseado em fatores impessoais e não em pessoais.

\subsection{Fatores condicionantes na adoção do método na empresa $B$}

O método de custeio adotado pela empresa B foi definido por uma consultoria contratada para reformular todo o sistema de informações de custos da empresa.

Segundo o diretor da empresa, a consultoria era formada por pessoas que trabalhavam com sistema de custos há muito tempo. Além dessa consultoria, um contador é terceirizado para trabalhar na manutenção do sistema.

A reformulação foi realizada com o objetivo de tornar o sistema mais ágil e rápido, principalmente para formular orçamentos e para gerar informações confiáveis que apoiassem a tomada de decisões da administração.

Esses objetivos são decorrentes da estrutura do mercado no qual a empresa opera (fatores contextuais). Segundo o diretor, a agilização do sistema foi necessária para que a empresa pudesse responder prontamente às exigências do mercado, onde preço é um fator decisivo para a colocação do produto. As exigências do mercado fizeram, portanto, com que a empresa adequasse o método de custos.

Para atingir esses objetivos, a empresa não realizou nenhuma modificação profunda no método adotado, apenas o adequou para gerar rapidamente informações para a administração (fatores organizacionais). $\mathrm{O}$ que não quer dizer que as informações geradas sejam confiáveis, já que a empresa utiliza o método de custeio por absorção para basear suas decisões administrativas. 
Pelo perfil da equipe que reformulou o sistema, contadores, pode-se justificar a manutenção do método por absorção no sistema de geração de informação de custos.

A reorganização foi realizada também atendendo ao perfil administrativo do diretor geral. O objetivo era levar ao diretor as informações que ele necessitava para manter seu modo administrativo. Ele delega responsabilidades operacionais para os subordinados, mas controla os resultados e toma todas as "decisões estratégicas", analisando as informações do relatório mensal.

Analisando essas informações, é possível fazer um resumo dos fatores que influenciaram a adoção do método de custeio:

- Fatores Contextuais - empresa atua em um mercado voltado para o consumidor final, esse ambiente é altamente competitivo e a disputa por mercado entre as empresas concorrentes ocorre principalmente por preço; os clientes exigem decisões rápidas quanto a preços e descontos. Apesar desse fator ter tido forte influência sobre as decisões de modificação do sistema de informações de custos que vinha sendo utilizado há vinte anos, esse não foi o fator predominante na adoção do método de custeio.

- Fatores Organizacionais - a empresa tem um perfil administrativo tradicional, os responsáveis pelo sistema de informações de custos são contadores e não administradores e possui uma boa estrutura de apoio. Esses fatores organizacionais foram definitivos para a adoção do método de custeio atualmente utilizado.

- Fatores Pessoais - o principal administrador da empresa centraliza em suas mãos as decisões estratégicas da empresa, e para isto ele utiliza, em relação aos custos, o relatório mensal de custos. Assim, a influência do empreendedor ocorreu apenas em relação ao relatório, deixando as decisões quanto ao funcionamento do sistema em si a cargo dos contadores.

\subsection{Fatores condicionantes na adoção do método na empresa $C$}

O método adotado pela empresa 3 foi desenvolvido pelo próprio empresário.

Segundo o empresário,

"Eu desenvolvi este método baseado na minha experiência. Consultei alguns livros e algumas pessoas, mas não adotei nenhum método descrito. O que eu faço eu mesmo que desenvolvi. O método que eu utilizo é muito mais prático e representa muito mais a minha realidade do que qualquer outro método. E o meu método é aceito, nenhum cliente me disse que eu estou errado. Eu conheço outro método de custeio (absorção), mas eu acho que se eu for aplicá-lo eu vou encontrar os mesmos valores que eu encontro com o método que eu desenvolvi”.

O empresário possui características de uma pessoa centralizadora que podem ser verificadas pelo excesso de funções que ele desenvolve dentro da empresa (concentra quase toda a parte administrativa em suas mãos). Isso é decorrente da estrutura enxuta que caracteriza a pequena empresa, mas também devido às características pessoais do empresário. Pelo contato mantido com ele, verificou-se que as decisões dentro da empresa são todas tomadas por ele, e quando foi necessário desenvolver um método de custeio, ele tomou a frente e fez da forma que julgou correta.

O sistema de informações de custos foi desenvolvido devido a uma necessidade do mercado (fator contextual). Um cliente da empresa pediu para que o empresário adotasse um método para o cálculo dos custos dos produtos que seriam negociados, porém o fator que condicionou a adoção do método foi pessoal.

Analisando essas informações, é possível fazer um resumo dos fatores que influenciaram a adoção do método de custeio:

- Fatores Contextuais - empresa atua em um mercado onde os preços são determinantes, mas a negociação com o cliente é que é decisiva, e não a concorrência direta entre empresas. $\mathrm{O}$ fator contextual pressionou a empresa a desenvolver um método de custeio que ganhasse pedidos.

- Fatores Organizacionais - a empresa não possui uma estrutura administrativa que apoie o empresário, porém esse fator não pesou na adoção do método de custeio, uma vez que o empresário possui características pessoais centralizadoras.

- Fatores Pessoais - o empresário é altamente centralizador; possui uma vasta experiência operacional, porém não possui conhecimentos gerenciais. Os fatores pessoais foram determinantes na adoção do método de custeio.

\subsection{Fatores condicionantes na adoção do método na empresa D}

O método adotado pela empresa foi desenvolvido pelo seu irmão, o empresário da empresa C. As duas empresas, por atuarem no mesmo mercado, serem 
vizinhas, dirigidas por irmãos e por terem um funcionário em comum (o engenheiro), mantêm um intercâmbio de informações muito grande.

Como o empresário D delega grande parte da responsabilidade administrativa para o engenheiro, e como ele mantém uma proximidade muito grande com a empresa $\mathrm{C}$, que em termos de utilização de ferramentas gerenciais estava mais preparada, então ele trouxe a experiência adquirida na outra empresa para a sua realidade.

Assim, são fatores determinantes na adoção do método utilizado no cálculo dos custos da empresa D: a utilização, há muitos anos, pela empresa $\mathrm{C}$ do método; a responsabilidade do engenheiro em relação à administração do negócio; e a proximidade física das duas empresas.

Analisando essas informações, é possível fazer um resumo dos fatores que influenciaram a adoção do método de custeio:

- Fatores Contextuais - a empresa atua no mesmo ambiente que a empresa $\mathrm{C}$, portanto os fatores são os mesmos.

- Fatores Organizacionais - a empresa não possui uma estrutura organizacional que apoie o administrador; cuja figura principal na empresa não é o empreendedor, mas o engenheiro, que também atua na empresa $\mathrm{C}$ e busca importar as ferramentas gerenciais desenvolvidas naquela empresa; há uma proximidade física entre a empresa $\mathrm{C}$ e a empresa D. Dessa forma, é conveniente para o empresário e principalmente para o engenheiro, que possui uma sobrecarga de trabalho, buscar formas administrativas já prontas e testadas em um ambiente parecido, do que adotar novas formas administrativas que não se tem conhecimento. Esses fatores foram os determinantes na adoção do método de custeio.

- Fatores Pessoais - o empresário é altamente descentralizador; transfere a responsabilidade da condução dos negócios para o engenheiro; e possui várias atividades além da empresa. Os fatores pessoais influenciaram a adoção do método através da omissão do empresário.

\section{Considerações finais}

Não existe a influência de apenas um tipo de fator na adoção dos métodos de custeio utilizados pelas empresas, o que ocorre é a influência conjunta dos fatores, mas com destaque maior para um deles (o que está em negrito na descrição dos fatores de cada empresa).
Os fatores contextuais foram determinantes para a empresa A, os fatores organizacionais para a empresa $\mathrm{B}$ e D e os fatores pessoais para a empresa C. É importante ressaltar que a análise da empresa como um todo apontou os fatores que foram preponderantes na adoção do método de custeio, porém, mesmo as empresas que tiveram maior influência de um mesmo tipo de fator, observou-se que os motivos que levaram àquele resultado são diferentes.

A identificação dos fatores que são preponderantes em cada caso passa pela análise da filosofia de administração de cada empresa. Essa filosofia, que em muitos casos não é estipulada racionalmente pelos administradores, mas é determinada por contingências, permeia a estrutura administrativa e direciona a forma de atuação dos administradores e das empresas como um todo.

A filosofia administrativa da empresa $\mathrm{C}$ se baseia nos valores do empresário. Essa forma de conduzir a empresa foi determinante na adoção do método de custeio, e, devido a isso, os fatores pessoais foram identificados como os de maior preponderância.

Na empresa D, a filosofia administrativa se baseia em valores de "ouvir os colaboradores". Embora o corpo técnico seja pequeno e pouco qualificado, há um sentido mais coletivo que a empresa $\mathrm{C}$, ainda que com características de baixa formalização. Essa forma administrativa direciona as ações, e assim a adoção do método de custeio também foi influenciada por essa filosofia. Os fatores organizacionais que são preponderantes neste caso, são os sinais de surgimento de um quadro administrativo precário.

Na empresa B, a filosofia administrativa se baseia na forma tradicional de administrar. A empresa possui uma estrutura formal de apoio administrativo baseado em um staff especializado, que foi formado desde quando a empresa era uma média empresa, e que continua com essas mesmas características. Isso levou os fatores organizacionais a serem o de maior influência na adoção do método de custeio.

Na empresa A, a filosofia administrativa está baseada na visão centrada no cliente e no mercado. Isso porque a empresa está inserida em uma gerra concorrencial forte, e a disputa pela liderança de mercado faz com que a empresa busque melhores informações de custos. Além disso, os dois empresários foram executivos em uma grande empresa do mesmo setor industrial e demonstraram um maior conhecimento de ferramentas gerenciais e de uso de uma administração profissional. Essa característica da administração levou, portanto, os fatores contextuais a serem os de maior relevância. 
Tabela 2 - Relação dos fatores de adoção do método de custeio e das filosofias administrativas

\begin{tabular}{|l|c|l|}
\hline Empresa & Fator de Maior Preponderância & Filosofia Administrativa \\
\hline Empresa C & Pessoal & Valores do empresário \\
\hline Empresa D & Organizacional & Valores de consulta aos colaboradores \\
\hline Empresa B & Organizacional & Valores de staff especializado \\
\hline Empresa A & Contextual & Valores do mercado \\
\hline
\end{tabular}

Com as informações até aqui identificadas, é possível confeccionar um quadro para visualizar melhor os fatores preponderantes e a filosofia administrativa de cada empresa.

A sequiência acima utilizada para apresentar as filosofias administrativas das empresas estudadas não foi aleatória. Buscou-se identificar um parâmetro que pudesse ser utilizado para comparar os estudos realizados nas empresas. O parâmetro identificado pelos autores foi o nível de pessoalidade/ impessoalidade. A Figura 1 ilustra um contínuo pessoalidade/impesoalidade, onde os extremos são apenas marcos teóricos de compreensão do fenômeno, pois, na realidade, nenhuma empresa é totalmente influenciada pela pessoalidade e com ausência de impessoalidade; ou então, de forma oposta, totalmente estruturada pela impessoalidade e livre de pessoalidade.

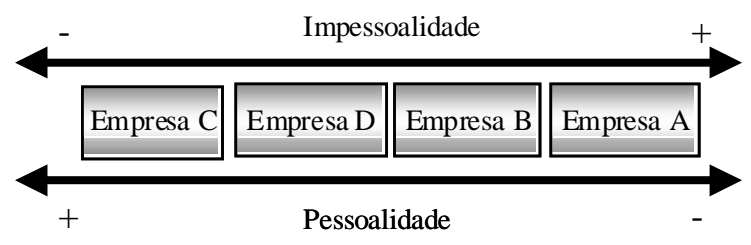

Figura 1 - Posição das empresas estudadas segundo o nível de pessoalidade/impessoalidade de suas filosofias administrativas

As empresas com quadro administrativo mais profissionalizado e qualificado são as que foram mais influenciadas pela impessoalidade nas decisões, enquanto que as empresas que possuem quadro administrativo menor tiveram maior influência de fatores pessoais.

Assim, em uma percepção exploratória do fenômeno, o condicionante primário na escolha do método de custeio na pequena empresa é a filosofia administrativa. Essa orientação das políticas e da organização varia desde um alto nível de pessoalidade (influência dos valores do empresário) até um alto nível de impessoalidade (influência de valores de mercado).

Dado que a pessoalidade fundamenta-se na intuição, na ausência de planejamento e na centarlização; e a impessoalidade fundamenta-se no cálculo, no planeja- mento e na profissionalização do quadro administrativo; pode-se inferir que as pequenas empresas com maior nível de impessoalidade tendem a explicitar a análise da adoção dos métodos de custeio segundo características técnicas e as de maior nível de pessoalidade tendem a reduzir a análise da adoção à introspecção do empresário, segundo sua experiência pessoal.

\section{Referências bibliográficas}

ALVES, N. J. Modelo conceitual de mensuração de resultados para micro e pequenas indústrias - um enfoque em gestão econômica, 1997. Dissertação (Mestrado) - Faculdade de Economia, Administração e Contabilidade, Universidade de São Paulo.

ANTUNES JÚNIOR, J. A. V.; KLIEMANN NETO, F. J.; MARTINS, S. S. Planejamento e controle de processos de fabricação pelo método das unidades de esforço de produção. s.1., 1991.

BREVIAN, P. A.; CERVO, A. L. Metodologia científica. São Paulo: Makron Books, 1996.

CATELLI, A.; GUERREIRO R.; SANTOS R. V. As críticas da teoria das restrições à contabilidade de custos: uma resposta. Revista de Contabilidade do Conselho Regional de Contabilidade de São Paulo. ano I, no 1, p.45-52, abr/1997.

CHING, H. Y. Gestão baseada em custeio por atividades: planejando com sucesso a implantação do ABM. São Paulo, Atlas, 1997.

CORBETT NETO, T. Contabilidade de Ganhos: a nova contabilidade gerencial de acordo com a Teoria das Restrições. São Paulo, Nobel, 1997.

FLORENTINO, A. M. Custos: princípios, cálculo e contabilização, $8^{\mathrm{a}}$ ed. Rio de Janeiro: Fundação Getúlio Vargas, Serviço de Publicações, 1983.

GONÇALVES, R. C. M. G.; PROCÓPIO, A. M.; CONCENZA, V. A. Diferentes métodos de custeio e a utilidade, confiabilidade e valor de feedback da 
informação de custo. Revista de Contabilidade do Conselho Regional de Contabilidade do Estado de São Paulo. ano II, no 4, p 5-10 mar/1998.

GUERREIRO, R. Notas de aula. $1^{\circ}$ semestre 1999. Disciplina - Contabilidade de Custos. Faculdade de Economia, Administração e Contabilidade, Universidade de São Paulo.

IOB - INFORMACOES OBJETIVAS. Tematica Contabil e Balancos. ano XXXII, n 36, p.6-9, 1ªsemana - set/ 1998.

KASSAI, S. As empresas de pequeno porte e a contabilidade, 1996. Dissertação (Mestrado) Faculdade de Economia, Administração e Contabilidade, Universidade de São Paulo.

KRAEMER H. T.; KLIEMANN NETO, F. J. A nova competição global e a necessidade de novos sistemas de custeio. IN: CONGRESSO BRASILEIRO DE GESTÃO ESTRATÉGICA DE CUSTOS, I., São Leopoldo, 1994. Anais, São Leopoldo, Ed. Unisinos, 1994. p.246-57.

KRAEMER, T. H. Discussão de um sistema de custeio adaptado às exigências da nova competição global, 1995. Dissertação (Mestrado). Universidade Federal do Rio Grande do Sul.

MARTINS, E. Contabilidade de Custos. São Paulo: Atlas, 1998.

PAIXÃO, L. Q.; KLIEMANN NETO, F. J. Utilização do custeio baseado em atividades em uma empresa de transporte rodoviário de carga (CD-ROM). IN:

Encontro Nacional de Engenharia de Produção, XXII., Curitiba, 2002. Anais, Curitiba, PUCPR, 2002.

PEREZ JÚNIOR, J. H.; OLIVEIRA, L. M.; COSTA, R. G. Gestão estratégica de custos. São Paulo, Atlas, 1999.

RESNIK, P. A bíblia da pequena empresa: como iniciar com segurança sua pequena empresa e ser muito bem-sucedido. São Paulo: Makron, McGrawHill, 1990.

SANTOS, R. V. Modelagem de sistemas de custeio. Revista de Contabilidade do Conselho Regional de Contabilidade do Estado de São Paulo. ano II, n ${ }^{\circ} 4$, p 62-74 mar/1998.

ZIMMERER, T. W.; SCARBOROUGH, N. M.

Essentials of small business management. New York: Macmillan College, 1994. 